\title{
Prolonged Bradycardia, Asystole and Outcome of High Spinal Cord Injury Patients
}

\author{
${ }^{1}$ Nissar Shaikh, ${ }^{2}$ Ali Raza, ${ }^{3}$ Atur Rahman, ${ }^{4}$ Adel Shabana, ${ }^{5}$ Faisal Malstrome, ${ }^{6}$ Ghaniem Al-Sulaiti
}

\begin{abstract}
High spinal cord injury ( $\mathrm{HSCl})$ is one of the devastating traumatic injuries. Majority of these patients are young male and $93 \%$ will have major neurological disabilities. The aim of this study was to know the prevalence, risk and precipitating factors for prolonged bradycardia in the $\mathrm{HSCl}$ patients.
\end{abstract}

Patients and methods: All patients who were admitted to the intensive care unit (ICU) of tertiary hospital, with spinal cord injury above level of dorsal (D4) were enrolled in this study prospectively. Patient's demographic data, mechanism, level and type of spinal injury, associated injuries, injury severity score (ISS), spinal shock, vasopressors used, time of occurrence of bradycardia; precipitating, risk factors and outcome were recorded.

Results: During the study period, total 138 patients were admitted to the intensive care unit with $\mathrm{HSCl}$. Majority of patients were male. The most frequently associated injury was skeletal fractures (38.4\%). Pneumonia in $56(41 \%)$ was the most common complication. Forty-five (33\%) patients had prolonged bradycardia; 53.4\% had cardiac asystole, 29 (21\%) patients had bradycardia during endotracheal suctioning, where, as $27(20 \%)$ patients developed bradycardia at positioning. $\mathrm{HSCl}$ patients with prolonged bradycardia had significantly higher, ISS score, ICU and hospitals stay. Multivariate analysis revealed that hypotension on admission; pneumonia and tracheostomy were risk factors for the development of prolonged bradycardia.

Conclusion: Prolonged bradycardia was associated with significantly higher incidence of asystole. Endotracheal suctioning and positioning of $\mathrm{HSCl}$ patients were provocative factors for prolonged bradycardia. Hypotension on admission, pneumonia and tracheostomy were the risk factors for development of prolonged bradycardia.

\footnotetext{
${ }^{1}$ Consultant/Assistant Professor, ${ }^{2}$ Senior Consultant and Associate Professor, ${ }^{3}$ SICU Fellow, ${ }^{4}$ Specialist, ${ }^{5}$ Director ${ }^{6} \mathrm{Head}$ and Senior Consultant

1,3 Department of Anesthesia/Intensive Care Unit and Perioperative Medicine, Hamad Medical Corporation, Qatar

${ }^{2,6}$ Department of Neurosurgery, Hamad Medical Corporation Qatar

${ }^{4}$ Department of Cardiology, Hamad Medical Corporation, Qatar

${ }^{5}$ Department of Surgical Intensive Care Unit, Hamad Medical Corporation, Qatar
}

Corresponding Author: Nissar Shaikh, Consultant/Assistant Professor, Department of Anesthesia/ICU and Perioperative Medicine, Hamad Medical Corporation, Qatar, Phone: 0097444392219, e-mail: nissatfirdous99@gmail.com
Keywords: Asystole, Atropine, Bradycardia, High spinal cord injury.

How to cite this article: Shaikh N, Raza A, Rahman A, Shabana A, Malstrome F, Al-Sulaiti G. Prolonged Bradycardia, Asystole and Outcome of High Spinal Cord Injury Patients. Panam J Trauma Crit Care Emerg Surg 2014;3(3):87-92.

Source of support: Nil

Conflict of interest: None

\section{RESUMEN}

La lesión de médula espinal alta ( $\mathrm{HSCl}$ ) es una de las lesiones traumáticas devastadoras. La mayoría de estos pacientes son jóvenes de sexo masculino y el $93 \%$ tendrán discapacidades neurológicas mayores. El objetivo de este estudio fue conocer la prevalencia, el riesgo y los factores precipitantes de bradycardia prolongada en los pacientes con $\mathrm{HSCl}$.

Pacientes y métodos: Todos los pacientes que fueron admitidos en la unidad de cuidados intensivos (UCI) del hospital de tercer nivel, con lesión de la médula sobre nivel dorsal (D4) fueron inscritos en este estudio de forma prospectiva. Datos demográficos del paciente, mecanismo, nivel y tipo de lesión en la columna, lesiones asociadas, puntuación de la gravedad de lesiones (ISS), choque espinal, vasopresores utilizados, el tiempo de aparición de bradycardia; se registraron los factores de riesgo precipitantes y los resultados.

Resultados: Durante el período de estudio un total de 138 pacientes fueron ingresados en la unidad de cuidados intensivos con $\mathrm{HSCl}$. La mayoría de pacientes fueron de sexo masculino. La lesión más frecuente asociada fueron las fracturas esqueléticas $(38,4 \%)$. La neumonía 56 (41\%) fue la complicación más común. $45(33 \%)$ pacientes tuvieron bradycardia prolongada; 53,4\% tenían asistolia cardíaca, 29 (21\%) pacientes tuvieron bradycardia durante la aspiración endotraqueal, así como 27 (20\%) pacientes desarrollaron bradycardia en el posicionamiento. Los pacientes $\mathrm{HSCl}$ con bradycardia prolongada tuvieron significativamente mayor, puntaje ISS, estadías en la UCI y hospitalaria. El análisis multivariado reveló que la hipotensión al ingreso; la neumonía y la traqueostomía fueron factores de riesgo para el desarrollo de bradycardia prolongada.

Conclusión: La bradycardia prolongada se asoció con una incidencia significativamente mayor de asistolia. La aspiración y posicionamiento endotraqueal de los pacientes $\mathrm{HSCl}$ fueron factores provocativos para bradycardia prolongada. La hipotensión al ingreso, la neumonía y la traqueotomía fueron los factores de riesgo para el desarrollo de bradycardia prolongada.

Palabras clave: Asistolia, Atropina, Bradycardia, Lesión de la médula espinal alta. 


\section{INTRODUCTION}

High spinal cord injury (HSCI) is one of the most serious traumatic injuries that occur to the human. These injuries can be caused by road traffic accidents, fall, diving injuries and fall of heavy object. High spinal cord injury has a serious pathological impact due to its involvement of central nervous as well as autonomic nervous system. The primary spinal cord injury lead to a major neurologica deficit and the secondary autonomic nervous system involvement causes sympathetic and parasympathetic imbalance resulting in occurrence of life threatening bradycardia, asystole, hypotension, ventricular and supraventricular tachycardia in initial days. The combine effect of these both system involvement increases the morbidity and mortality in these patients.

High spinal cord injury is the spinal cord injury above fourth dorsal vertebra. Bradycardia is one of the most common cardiac abnormalities in HSCI patients. When bradycardia persist for more than the usual period (> 7 days) it is termed as prolonged bradycardia. ${ }^{1}$ It can progress to life threatening cardiac asystole. In HSCI, there will be sympathetic out flow cut off, but the intact parasympathetic flow will take the upper hand, leading to parasympathetic dominance and various cardiac conduction abnormalities. The cardiac involvement can be acute or progress to chronic cardiac abnormalities leading to chronic cardiac disease. The cardiac disease is the most common cause of mortality in HSCI patients. ${ }^{2}$ There is scanty literature about provocative and risk factors and management of prolonged bradycardia in HSCI patients.

The aim of this study was to know the prevalence, duration, risk and precipitating factors for prolonged bradycardia, and its association with pneumonia, positioning or endotracheal suction in the HSCI patients.

\section{Patients and Methods}

All patients admitted to the intensive care unit (ICU) of tertiary hospital with spinal cord injury above level of dorsal 4th vertebra from January 1995 to December 2010 were enrolled prospectively in this study.

Patient's demographic data, mechanism of injury and associated injuries, level and type of spinal injury, injury severity score, spinal shock, vasopressors used, time of occurrence of bradycardia, treatment of bradycardia, chest X-ray finding at the time of bradycardia, relation of bradycardia with endotracheal suctioning or patient's position, ICU stay, tracheostomy, and outcome were recorded. Patients with acute myocardial infraction, traumatic cardiac arrest, and asystole due to other etiological reasons were excluded.
Bradycardia was defined as documented heart rate of less than 50 beats/minute. When bradycardia was persisting for more than seven days it is termed as prolonged bradycardia. Hypotension was defined as the systolic blood pressure of less than $90 \mathrm{~mm} \mathrm{Hg}$. Asystole was an acute event with prolonged bradycardia, followed by loss of pulse and blood pressure requiring cardiorespiratory resuscitation. Pneumonia was diagnosed as per center for disease control (CDC) criteria. Medical therapy for bradycardia included intravenous (IV) atropine, adrenaline and aminophylline. Vasopressors used were noradrenalin, adrenaline and dopamine. Complications occurred during the study such as atrial fibrillation, pneumonia, septic shock, multiorgan failure, acute renal failure, gastroparasis, paralytic ileus, gastrointestinal bleeding, bed sore, urinary tract infection and hyperthermia were recorded. Ethical approval was obtained for the study from institutional research committee.

\section{Statistical Methods}

Data were entered in SPSS version 19.0 Statistical Package. Descriptive statistics in the form of frequency and percentages were calculated for categorical variables, and mean \pm SD were calculated for interval variables. Chisquare tests were performed to see association between prolonged bradycardia and no prolonged bradycardia for all the categorical variables, whereas Students t-test and Wilcoxon's rank sum test, wherever applicable, were performed for interval variables. Logistic regression with enter method, taking important variables for prolonged bradycardia has been used to see risk factors

Table 1: Demographic characteristics and clinical findings

\begin{tabular}{ll}
\hline Variables & Number (\%) \\
\hline Gender & $132(95.6)$ \\
Male & $6(4.4)$ \\
Female & \\
Prolong bradycardia & $45(33)$ \\
Yes & $93(67)$ \\
No & $122(88.4)$ \\
Survived & $16(11.6)$ \\
Died & \\
Cause of death & $16(11.6)$ \\
Total & $4(2.9)$ \\
Septic shock & $4(2.9)$ \\
Multiple organ failure syndrome (MOFS) & $15(10.8)$ \\
Pneumonia & \\
Level of injury & $10(7.2)$ \\
C1-C4 & $6(4.3)$ \\
C5-C8 & \\
Mechanism of injury & $9(6.5)$ \\
RTA (Road traffic accident) & $2(2.1)$ \\
FOHO (Fall of heavy object) & $5(3.6)$ \\
Fall from height &
\end{tabular}




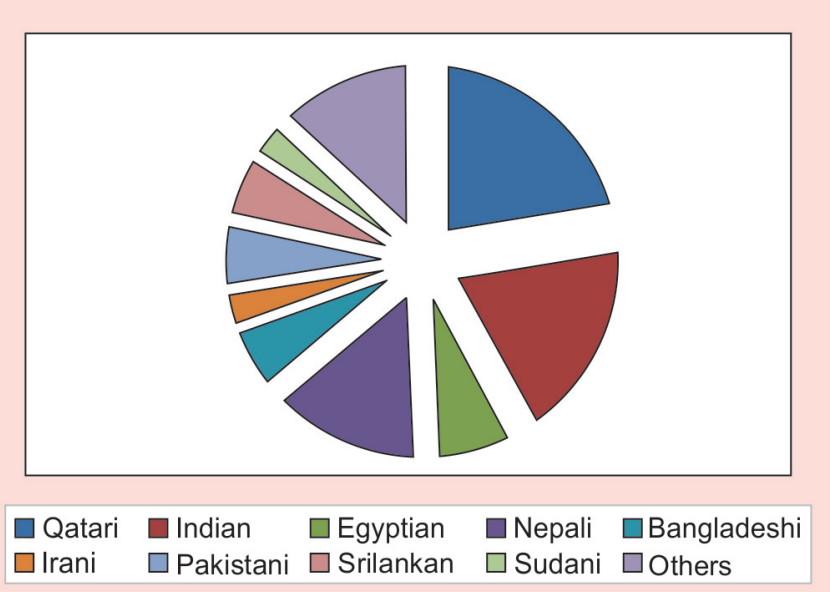

Graph 1: Patients division according to nationalities

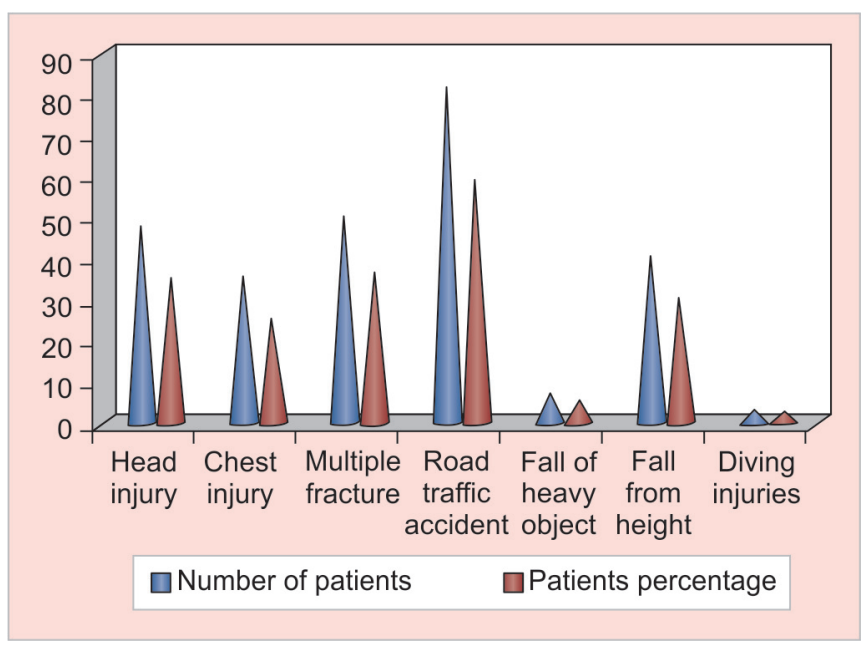

Graph 2: Etiology and associated injuries

Table 2: Mechanism of injury and clinical parameters according to the prolonged bradycardia

\begin{tabular}{|c|c|c|c|}
\hline Variable & $\begin{array}{l}\text { Prolonged } \\
\text { bradycardia n (\%) }\end{array}$ & $\begin{array}{l}\text { No prolonged } \\
\text { bradycardia } n(\%)\end{array}$ & $p$-value \\
\hline Total number & $45(33)$ & $93(67)$ & \\
\hline Cardiac asystole & $24(53.3)$ & $4(4.3)$ & 0.001 \\
\hline Head injury & $20(44.4)$ & $32(34.4)$ & 0.25 \\
\hline Chest injury & $13(28.9)$ & $24(25.8)$ & 0.7 \\
\hline Fractures & $16(35.6)$ & $37(39.8)$ & 0.63 \\
\hline RTA (Road traffic accident) & $24(53.3)$ & $60(64.5)$ & 0.25 \\
\hline FOHO ( Fall of heavy object) & $3(6.7)$ & $5(5.4)$ & 0.76 \\
\hline FFH (Fall from height) & $18(40)$ & $25(26.9)$ & 0.12 \\
\hline Diving injury & $1(2.2)$ & $2(2.2)$ & 0.98 \\
\hline Hypotension at admission & $40(88.9)$ & $13(14)$ & 0.001 \\
\hline Bradycardia while changing position & $27(60)$ & $3(3.2)$ & 0.001 \\
\hline Bradycardia on endotracheal suction & $29(64.4)$ & $2(2.2)$ & 0.001 \\
\hline Septic shock & $7(15.6)$ & $1(1.1)$ & 0.001 \\
\hline MODS (Multiple organ dysfunction syndrome) & $15(33.3)$ & $0(0)$ & 0.001 \\
\hline Vasopressors & $41(91.1)$ & $14(8.9)$ & 0.01 \\
\hline Complication & $34(75.6)$ & $88(94.6)$ & 0.001 \\
\hline Treatment for bradycardia & $43(95.6)$ & $3(3.2)$ & 0.001 \\
\hline Atropine & $42(93.3)$ & $3(3.2)$ & 0.001 \\
\hline Adrenaline & $3(6.7)$ & $0(0)$ & 0.01 \\
\hline Aminophylline & $5(11.1)$ & $0(0)$ & 0.001 \\
\hline Pacemaker & $1(2.2)$ & $0(0)$ & 0.15 \\
\hline Surgery & $28(62.2)$ & $40(43)$ & 0.03 \\
\hline Tracheostomy & $35(77.8)$ & $10(10.8)$ & 0.001 \\
\hline
\end{tabular}

and presented with adjusted odds ratios (OR) and 95\% confidence interval (CI). Two tailed p-value has been considered for statistical significant level.

\section{RESULTS}

Total 138 patients were admitted to the ICU with HSCI and $45(33 \%)$ had prolonged bradycardia. Majority of patients were male. Average ISS score was 37.4 and average age was 35.62 years. Total $16(11.6 \%)$ patients died, majority of them 9 (65\%) were involved in RTA, $15(94 \%)$ had developed pneumonia which lead to septic shock 4 (25\%) patients with multiple organ failure (MOF) (Table 1).
These HSCI was common in local population (22.5\%) followed by Indians (19.6\%), Nepali (13.8\%) and Egyptians (Graph 1). Most common mechanism for HSCI was RTA $(60.9 \%)$, fall, fall of heavy objects in 31.2 and $5.8 \%$ patients respectively (Graph 2). The most frequently associated injury in these patients was skeletal fractures (38.4\%), head injuries (37.7\%) and chest trauma in 26.8\% (Graph 2).

Table 2 shows that prolonged bradycardia patients had significantly higher asystole (53.3 vs $4.3 \%, \mathrm{p}=0.001$ ), hypotension (88.9 vs 14\%, p = 0.001). Significantly higher incidence of bradycardia while changing position $(60 \%$ vs $3.2 \%, \mathrm{p}=0.001$ ), and endobronchial/endotracheal suc- 
Table 3: Interval characteristic according to prolonged bradycardia

\begin{tabular}{llll}
\hline & $\begin{array}{l}\text { Prolonged } \\
\text { bradycardia } \\
\text { mean } \pm S D\end{array}$ & $\begin{array}{l}\text { No prolonged } \\
\text { bradycardia } \\
\text { mean } \pm S D\end{array}$ & p-value \\
\hline Age & $38 \pm 14$ & $34 \pm 12$ & 0.55 \\
ICU stay & $38.8 \pm 29$ & $9.6 \pm 11.9$ & 0.001 \\
Hospital stay & $63 \pm 55$ & $27 \pm 34$ & 0.002 \\
ISS score & $43.5 \pm 14$ & $34.4 \pm 16.5$ & 0.02 \\
\hline
\end{tabular}

ICU: Intensive case unit; ISS: Injury severity score

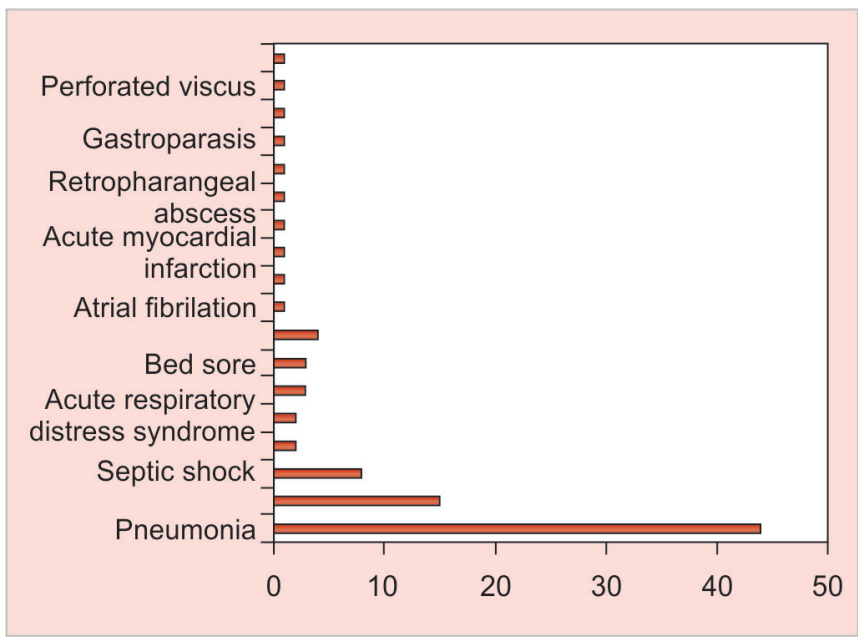

Graph 3: Complications associated with high spinal injuries

tioning $(64.4 \%$ vs $2.2 \%, \mathrm{p}=0.001)$. Prolonged bradycardia group of patients required higher vasopressors to support their hemodynamic ( $91.1 \%$ vs $8.9 \%, \mathrm{p}=0.001)$. Patients with prolonged bradycardia had significantly more complications (75.6 vs 94.6\%, $\mathrm{p}=0.001$ ). $95.6 \%$ patients received medical treatment in prolonged bradycardia group whereas $3.2 \%$ patients were given medical treatment in no prolonged bradycardia group (Table 2).

Prolonged bradycardia group of patients had significantly higher ISS score ( $43.5 \pm 14$ vs $34.4 \pm 16.5, \mathrm{p}=0.02)$, significantly prolonged ICU (38.8 \pm 29 vs $9.6 \pm 11.9, \mathrm{p}=$ $0.001)$, and hospital stay $(63 \pm 55$ vs $27 \pm 34, \mathrm{p}=0.002)$ (Table 3).

Multivariate analysis after adjusting important variables, pneumonia, outcome, surgery and complications revealed that hypotension $(\mathrm{OR}=10.66,95 \%$ C.I. $2.8-40.6$, $\mathrm{p}=0.001)$, pneumonia $(\mathrm{OR}=3.5,95 \%$ CI $0.9-14.0, \mathrm{p}=$ $0.05)$ and tracheostomy $(\mathrm{OR}=6.3,95 \%$ C.I. $1.67-23.5$, $\mathrm{p}=0.006$ ) were the risk factors for the development of prolonged bradycardia in HSCI patients. Tracheostomy was performed six times higher in prolonged bradycardia group of patients (Table 4).

In our study the most common complication (40.57\%) was pneumonia (50 patients), which lead to multiorgan failure (15 patients), septic shock in eight patients, gastrointestinal bleeding in four patients and bedsores in three patients (Graph 3).
Table 4: Multivariate analysis and risk factors for bradycardia

\begin{tabular}{|c|c|c|c|}
\hline Variables & $\begin{array}{l}\text { Adjusted } \\
\text { OR }\end{array}$ & $95 \% \mathrm{Cl}$ & $p$-value \\
\hline Hypotension (at admission) & 10.7 & $2.8-40.0$ & 0.001 \\
\hline Pneumonia & 3.5 & $0.9-14.0$ & 0.05 \\
\hline Outcome & 3.0 & $0.05-1.7$ & 0.17 \\
\hline Surgery & 1.4 & $0.4-4.7$ & 0.63 \\
\hline Tracheostomy & 6.3 & $1.7-24.0$ & 0.006 \\
\hline Complications & 2.0 & $0.5-7.5$ & 0.29 \\
\hline
\end{tabular}

$\mathrm{Cl}$ : Confidence interval; OR: Odds ratio

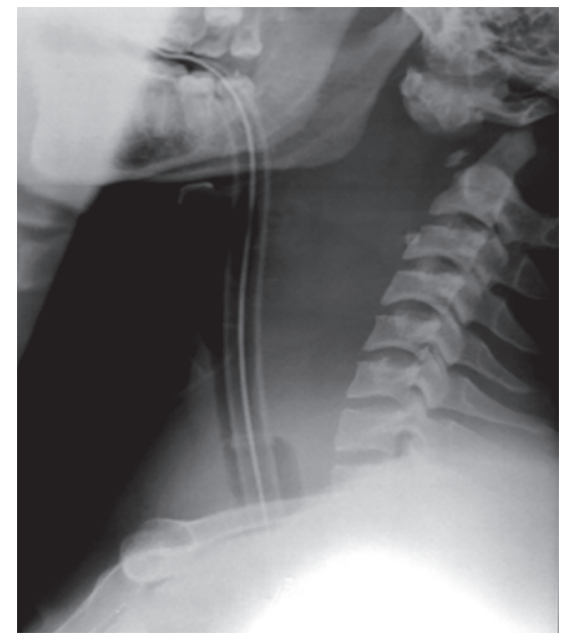

Fig. 1: High cervical spine injury

\section{DISCUSSION}

High spinal cord injury is one of the major traumatic injuries. Eighty percent of these patients are young male and $93 \%$ of them will have major neurological disabilities (Fig. 1). Hence, these injuries had a great financial impact on patient's family as well as the national healthcare system. ${ }^{2,3}$ These HSCI will cut off the sympathetic nervous supply below the level of the injury. The parasympathetic control is directly through vagus nerve, and the preganglionic fibers synapse with the postganglionic parasympathetic neurons occur near the myocardium, where as the sympathetic preganglionic neurons are situated within the lateral horns of D1 to L2 in the spinal cord. When HSCI occur the sympathetic supply to heart is served but parasympathetic control to the myocardium is intact. In the normal circumstances autonomic control to the heart is balanced as sympathetic and parasympathetic supply antagonizes each other, but if one of them is absent other will dominate. It leads to the various cardiovascular conduction abnormalities; such as bradycardia, life-threatening cardiac arrhythmia, cardiac conduction defects and hypotension. ${ }^{4}$ If higher is the level of the spinal cord injury, involvement of the cardiovascular system will be more profound. Cardiovascular complication in HSCI patients are the leading factor for the increased morbidity and mortality. ${ }^{2}$ 
The most frequent cardiac abnormality associated with HSCI is bradycardia. Initial bradycardia occurs in all patients with HSCI with spinal shock. When a patient recovers from spinal shock, the heart rate increases, commonly within a week (7 days) of injury, but in few patients bradycardia can persist up to 6 weeks.

Lehmann et $\mathrm{al}^{1}$ found that bradycardia occurs in all patients with cervical spine injuries and $15 \%$ of these patients will have cardiac asystole. Moerman et $\mathrm{al}^{5}$ also reported the same percentage of cardiac asystole. In our study, $33 \%$ of these HSCI had prolonged bradycardia. Fifty three percent $(53 \%)$ of the prolonged bradycardia patients had asystole. The time of onset and duration of bradycardia is variable, and it is not well standardized in the literature; there is paucity of literature about prolonged bradycardia. Piepmeier et al reported high incidence of bradycardia upto 5 post injury days and then declines rapidly in HSCI patients. ${ }^{6}$ Moerman et al described mean time of bradycardia 5 to 7 days and $15 \%$ of them had asystole. Franga et $\mathrm{al}^{7}$ reported that $16 \%$ of their patients had asystole.

Our study reconfirms that the endotracheal suctioning and positioning of HSCI patients is significantly associated with bradycardia and asystole. HSCI patients will have increased bronchial secretions as a result of vagal dominance or bronchial infection hence requiring frequent airway secretion suctioning and positioning. Normal response to this maneuver is tachycardia but in HSCI patient parasympathetic dominance leads to bradycardia and cardiac asystole; because of this etiological reseason; use of ipatropium bromide may decrease the incidence of bradycardia and asystole. ${ }^{8} \mathrm{HSCI}$ patients are at the increased risk for the development of pneumonia and it is the most frequent complication in our study. The higher level of spinal injury, will be increased the risk of pneumonia. As these patients are unable to clear the bronchial secretions; due to weaker cough reflex as a result of weakness or paralysis of the muscles of respiration. The combined effect of all these factors is retention of bronchial secretions, thickening of secretion, atelectasis and development of pneumonia. ${ }^{9}$ In our study, pneumonia was the major risk factor for the development of prolonged bradycardia and asystole in HSCI patients. In HSCI patients the normal response to hypoxia is absent due to sympathetic flow cut off, so when these patients develops pneumonia as the pulmonary inflation reflex is absent, there will be no tachycardia, but dominant parasympathetic flow will cause bradycardia and asystole. ${ }^{6,10}$

Gilgoff et $\mathrm{l}^{11}$ reported a case of $\mathrm{HSCI}$, who developed pneumonia and which led to bradycardia requiring pacemaker and Holter monitoring; and with interrogation of holter monitoring it revealed that there was seven fold increased in pacemaker activity indicating that pneumonia causing increased incidence of life-threatening bradycardia and asystole.

Our study demonstrated that pneumonia was a significant risk factor for prolonged bradycardia and asystole with odd ratio of 3.48 and 95\% CI (0.88-14.2) (Table 4). We also found that initial spinal shock and tracheostomy were significant risk factors for the development of prolonged bradycardia and cardiac asystole. Spinal shock or hypotension on admission occurs in HSCI patients is due to the decreased vascular tone as a consequence of afferent sympathetic pathway disruption, vasodilatation, absence of reflex tachycardia, in combination with direct negative inotropic vagal effect on the myocardium. ${ }^{7}$ Spinal cord injury patients will require a tracheostomy to support respiration and ventilation. The need for tracheostomy is significantly higher in patients with HSCI. ${ }^{12}$ We found a significant correlation between tracheostomy and occurrence of prolonged bradycardia and asystole. This might be due to the combine effect of high injury level, higher incidence of pneumonia, more bronchial secretion requiring more suctioning as well as positioning of these patients.

Majority of our patients had medical management for bradycardia and asystole, which included atropine sulphate, adrenaline and aminophyline. Only one patient had pacemaker insertion and it has to be removed due to infection. Our patients responded well to the medical therapy but the incidences of asystole were higher, may be related to the medical therapy and occurrence of pneumonia. Recent literature dictates that the pacemaker in HSCI patients to prevent life-threatening bradycardia and asystole. ${ }^{13}$ Cardiac pacemaker insertion is not free from complications, (death, failure to pace and infection). Franga et al found that risk are relatively minimal when compared to benefits in HSCI patient in the prevention of life, threatening bradyarrhythmia and asystole. ${ }^{7}$

Overall mortality of HSCI in our study was $11.6 \%$, which is comparable with that described in the literature. ${ }^{13,14}$ All patients with worst outcome had prolonged bradycardia and significant percentage (95.4\%) of them had pneumonia.

Future larger studies are needed in comparison of pacemaker and medical therapy, in preventive measures with initial use of ipatropium bromide nebulization, and kinetic rotation therapy.

\section{CONCLUSION}

HSCI remains a serious life-threatening trauma, as it involves both central nervous system and autonomic nervous system. Bradycardia is the most common arrhythmia occurring in these patients, significant percentage 
of HSCI patients can have prolonged bradycardia and asystole. Prolonged bradycardia in HSCI patients is associated with significant higher incidence of asystole. Endotracheal suctioning and positioning of HSCI patients were significant provocative factors for the occurrence of prolonged bradycardia. We also found that hypotension on admission, pneumonia, and tracheostomy were the significant risk factors for the development of prolonged bradycardia in HSCI patients. Majority of our patients responded well to the medical therapy, with slight higher incidence of asystole. Pneumonia was a significant risk factor for mortality in HSCI patients. In our study in spite of significant prolonged bradycardia and higher incidence of asystole, the outcome was comparable.

\section{KEY POINTS}

i. RTA was common etiology and skeletal injury was most frequently associated injury in HSCI patients.

ii. Prolonged bradycardia in HSCI patients is associated with significant increased incidence of asystole.

iii. Endotracheal suctioning and positioning of HSCI patients are provocative for bradycardia.

iv. Spinal shock, pneumonia and tracheostomy are the significant risk factors for the development of prolonged bradycardia in HSCI patients.

v. Prolonged bradycardia significantly increases the ICU as well as hospital stay of HSCI patients.

vi. In spite of higher incidence of prolonged bradycardia and asystole; medical management was effective.

\section{REFERENCES}

1. Lehmann KG, Lane JG, Pie meter JM, Batsford WP. Cardiovascular abnormalities accompanying acute spinal cord injury in Humans: Incidence, time course and severity. J Am Coll Cardiol 1987;10(1):46-52.
2. Grigorean VT, Sandu AM, Popescu M, Iacobini MA, Stoian R, Neascu C, et al. Cardiac dysfunction following spinal cord injury. J Medicine and Life 2009 Apr-Jun;2(2):133-145.

3. McMahon D, Tutt M, Cooks AM. Pharmacological management of hemodynamic complications following spinal cord injury. Orthopedics 2009;32(5):331.

4. Krassioukov AV, Karlsson AK, Wecht JM, Wuermser LA, Mathias CJ, Marino RJ. Assessment of autonomic dysfunction following spinal cord injury: rationale for additions to international standards for neurological assessment. JRRD 2007;44(1):103-112.

5. Moerman JR, Christie B, Sykes LN, Vogel RL, Nolan TL, Ashley DW. Early cardiac Pacemaker placement for life threatening bradycardia in spinal cord injury. J Trauma 2011 Jun;70(6):1485-1488.

6. Piepmeier JM, Lehman KG, Lane JG. Cardiovascular instability following spinal cord trauma. Cent Nerv Sys Trauma 1985;2(3):153-160.

7. Franga DL, Hawkins ML, Medeiros RS, Adewumi D. Recurrent asystole resulting from high cervical spinal cord injuries. American Surgeon 2006 Jun;72(6):525-529.

8. Dicpinigaitis, Spungen AM, Bauman WA, Absgarten A, Al menoff PL. Bronchial hyper responsiveness after cervical spinal cord injury. Chest 1994 Apr;105(4):1073-1076.

9. Jackson AB, Groomes TE. Incidence of respiratory complication following spinal cord injury. Arch Phys Med 1994 Mar; 75(3):270-275.

10. Sangvi AV, Chhabra HS, Nigam V, Tandon V, Mascarenhas AA. Permanent cardiac pacemaker for cardiac arrest following cervicodorsal spinal injury. Eur Spine J 2009 Jul; 18(suppl 2):S254-S257.

11. Gilgoff IS, Ward SL, Hohn AR. Cardiac pace maker in high spinal cord injury. Arch Phys Med Rehabil 1991;72:601-603.

12. Como JJ, Sutton ERH, McCunn M, Dutton RP, Johnson SB, Arabi B, Scalea TM. Characterizing the need for mechanical ventilation following cervical spinal cord injury with neurological deficit. J Trauma 1991 Jul;72(8):601-603.

13. Rangappa P, Jeyadoss J, Flabouris A, Clark JM. Marshall R. Cardiac pacing in patients with a cervical spinal cord injury. Spinal Cord 2010 Dec;48(12):867-871.

14. Bilello JF, Davis JW, Cunningham MA, Groom TF, Lemaster D, Sue LP. Cervical spinal cord injury and need for cardiovascular interventions. Arch Surg 2003 Oct;138(10): 1127-1129. 